\title{
A Resilient Environment through The Integration of CCA and DRR: An Overview of Existing Challenges
}

\author{
Nuwan Dias", Georgina Clegg ", Dilanthi Amaratunga \#, Richard Haigh \# \\ \# Global Disaster Resilience Centre, University of Huddersfield, Queensgate, Huddersfield, HD1 3DH, United Kingdom \\ E-mailn.dias@hud.ac.uk,g.clegg@hud.ac.uk,d.amaratunga@hud.ac.uk,r.haigh@hud.ac.uk
}

\begin{abstract}
Creating a resilient environment for disasters is a primary contemporary challenge. Disaster Risk Reduction (DRR) and Climate Change Adaptation (CCA) are well-known concepts, and practices used to reduce vulnerability and thereby contribute to the creation of a resilient environment. There is growing recognition that the theory and practice of CCA and DRR are converging and therefore, CCA and DRR efforts should be integrated to bring about effective solutions to reduce vulnerability and to create a resilient environment to disasters. However, the integration of CCA and DRR has always been a challenge due to several factors that hinder the process. Asia is highly vulnerable to disasters due to its geographical location, unplanned development, undistributed internal migration for urban areas and so on. Within this context, it is extremely important that the region undertakes strategies to create a resilient environment. In order to create a resilient environment, CCA and DRR integration plays a vital role, but within the current social, economic, political and demographic context of Asia, integration of CCA and DRR has become difficult. Based on the findings of a global analysis conducted as part of the research project ESPREssO, funded by the EU Horizon 2020 programme, this paper provides a critical review of the existing challenges associated with integrating DRR and CCA in order to create a resilient environment in Asia. During the first phase of the study, a narrative desk-based literature review was conducted, and during the second stage, extensive primary data collection was undertaken. The primary data collection methods were semi-structured expert interviews, expert focus group discussions, and an online questionnaire survey. Analysis revealed that a chaotic institutional set-up, political priorities, funding issues, stakeholder interests, and communication barriers are the prominent challenges to the integration of CCA and DRR in Asia, which must be overcome in order to establish a resilient environment.
\end{abstract}

Keywords - resilient environment; integration; CCA and DRR; challenges.

\section{INTRODUCTION}

The notion of disaster resilience is not new. The original concept of resilience derives from the Latin word resilio, meaning 'jump back' or 'bounce back.' This concept has become more prevalent and significant alongside the upsurge in the frequency and severity of disasters in recent times. UNISDR [1] defines disaster resilience as "the ability of a system, community or society exposed to hazards to resist, absorb, accommodate, adapt to, transform and recover from the effects of a hazard in a timely and efficient manner, including through the preservation and restoration of its essential basic structures and functions through risk management".

Disaster Risk Reduction (DRR) and Climate Change Adaptation (CCA) are key means to decrease the vulnerability of people and natural and man-made assets to disasters. The key aim of DRR is to reduce the destruction instigated by natural hazards through the "systematic development and application of policies, strategies, and practices to avoid (prevention) or limit (mitigation and preparedness) the adverse effects of hazards" [2]. DRR initiatives have the ability to reduce the negative impact of hazards and contribute to sustainable development [3].

In addition, climate change is contributing to increased global temperatures, sea level rise and the increased frequency and intensity of extreme climate-related hazards. CCA looks to tackle these issues through a "process of adjustment to actual or expected climate and its effects, in order to moderate harm or exploit beneficial opportunities" [4]. The interplay between CCA and DRR is gaining increasing attention [5], and it is recognized that there is a need for methodical linkages within CCA and DRR to advance sustainable development [6].

In addition to the increasing frequency and intensity of hazards, international demographic trends imply that more people are living in areas susceptible to sudden-onset natural disasters. Further, it is predicted that the world's population is expected to surpass nine billion by 2050 , with more than half living in Asia, mostly in urban areas [7]. In Asia's developing nations, $30 \%$ of the urban people live in slums and squatters [8]. National disasters have quadrupled over the past four decades with over US\$25 billion of natural 
disaster damages recorded in South Asia during the last five years alone [9]. Rapid urbanization and increasing population density puts greater pressure on land and services and if not correctly managed leads to the development of settlements in hazard-prone areas, inadequate resource management, lack of capacities, unclear mandates for DRR and uncoordinated emergency services at the local level [10]. Since Asia is particularly vulnerable to disasters, it is extremely important to find possible ways and means to reduce disaster risk, in order to lessen the vulnerability of Asian societies. In order to do this Asia needs to identify what are the positive consequences of the integration of CCA and DRR towards creating a disaster resilient environment and associated challenges.

Accordingly, this paper intends to recognize how the integration of CCA and DRR can support the creation of a disaster resilient environment and to investigate the current challenges facing integration in the context of Asia. Section 2 describes the methodology supporting this study. Section 3 delivers a theoretical explanation of how the integration of CCA and DRR would create a resilient environment while introducing other related notions. Section 4 is based on the primary data analysis which is presented together with a description of the challenges to integrating CCA and DRR in Asia. Section 5 concludes the findings with recommendations.

\section{MATERIAL AND METHOD}

This paper is grounded on the outcomes of a global synthesis on legal, policy and science approaches within the frame of CCA and DRR, conducted by a project entitled ESPREssO (Enhancing Synergies for Disaster Prevention in the European Union), funded by the EU Horizon 2020 programme. ESPREssO aims at contributing to a new strategic vision to approach natural risk reduction and climate change adaptation, thereby opening new frontiers for research and policymaking.

The key objectives of this paper are to (i) indicate the importance of the integration of CCA and DRR to create resilient environments and (ii) to review the challenges facing CCA and DRR integration in Asia. Accordingly, the methodology was developed to achieve these two key objectives.

The first objective was achieved through a narrative literature review and the second objective was achieved through primary data analysis. The literature review identified the key concepts underpinning this research. Accordingly, the notion of disaster resilience, the notions of DRR and CCA and the current status of integration were discovered. In the latter part of the literature review, it was revealed how the integration of CCA and DRR could benefit disaster resilience.

The second objective was achieved through a primary data collection exercise which included a series of semistructured interviews, focus group discussions and a questionnaire survey. Six interviews were conducted with disaster resilience and CCA experts from Asia. The sample consisted of academics, practitioners, NGOs, representatives from government bodies and so forth. In addition to semistructured interviews, three focus group discussions were conducted with five to six participants in each. Once the data was gathered, it was qualitatively analyzed using QSRNVivO Version 11 and thereafter, based on the identified key themes, mind maps were developed to understand the context of each issue and to identify the challenges.

Finally, to gain a wider perspective on the key challenges, an online questionnaire was developed. The survey was mainly designed to rate answers on a five-point Likert scale, which allows participants to specify their level of agreement, 1 being 'strongly disagree,' and 5 being 'strongly agree.' The questionnaire was completed by 78 highly experienced disaster resilience and CCA experts in Asia. The collected data was analyzed through the Relative Importance Index (RII) method, where ' $\mathrm{W}$ ' is the weight given to each factor, ' $A$ ' is the highest weight and ' $N$ ' is the number of respondents. Results of the questionnaire survey support the validation of the qualitative analysis findings.

\section{A. What is disaster resilience?}

The original concept of disaster resilience endorsed the concept of bouncing back to the original state after a disaster. But, many researchers did not endure with this notion as they argued that it did not capture the altered existence after a disaster and the new potentials that could emerge ([11], [12]). Accordingly, the notion of 'bounce forward' arose promoting the idea that disaster resilience is not only about resisting and recovering from a disaster but that it should also increase the ability of the public to realize from the disaster and to develop the networks, systems, and capabilities to a higher level for more resilient future.

Accordingly, the concept of disaster resilience can be explored from different standpoints. Generally, disaster resilience can be introduced as the ability of a system or an environment to adjust, recover and move forward after a disaster without damaging or interrupting its general functionality.

\section{B. What is disaster risk reduction?}

There are different views on the occurrence of the concept of DRR. As Wisner, Gaillard, and Kelman emphasize, the concept of DRR evolved from the concepts of emergency management and disaster management [13]. Initially, emergency management and disaster management were the key notions to reduce risk and vulnerabilities. Conversely, due to the confines of the disaster management concept in working with increasingly frequent and complex disasters, international frameworks initiated to substitute disaster management with the concept of disaster reduction, and later disaster risk reduction [14].

Many DRR policies and strategies view disasters as socioeconomic and political in origin, reflecting a school of thought recognized since the 1970s. They think the wider social, political, environmental and economic environments in which a hazard is situated. This is in contrast to the previous view of disasters as unavoidable 'natural events' that needed to be managed. Since disasters are created by the wider social, political, environmental and economic environment, they can be managed and reduced by social, political, environmental and economic actors ([15], [16]).

DRR refers to a wide range of opportunities for risk abatement and disaster management. Risk reduction includes prevention, preparedness, and part of the recovery process, 
and it gives particular emphasis to the reduction of vulnerability ([17], [18]). As UNISDR explains, disaster risk reduction is aimed at preventing new and reducing existing disaster risk and managing residual risk, all of which contribute to strengthening resilience and to the achievement of sustainable development [1].

\section{What is climate change adaptation?}

Climate change policy discussions initially focused upon a clear insistence to address the origins of climate change, i.e., concentrating on reducing greenhouse gas emissions from human activities. Whilst this remains a vital activity, climate change impacts at the local level are becoming a reality ([19], [20]). As a result, international policy discussions began to focus on a need to 'adapt' [21].

The IPCC defines CCA as, "The process of adjustment to actual or expected climate and its effects, in order to moderate harm or exploit beneficial opportunities" [4].

The concept of CCA is very broad. CCA, along with DRR, entails constructions or reconstructions of subsystems for the purpose of response to stressors and involve operations such as "avoiding," regulating/blocking reducing vulnerability, transforming the stressors and /or the social system as a whole [22]. CCA strategies exist through local and global scales, from community level responses to local, national and international government interventions ([21], [23]). At the community level, strategies include developments to agricultural systems such as crop diversification or the introduction of hazard-resistant crop varieties; risk assessments and associated plans; the protection of natural resources; early warning systems; education and awareness measures and protection of water resources [21]. At the national level for the least developed countries, some countries have developed National Adaptation Programmes of Action (NAPAs). NAPAs identify areas in which adaptation strategies are essential in mitigating against adverse climate change effects [20].

\section{Synergies between CCA and DRR}

A number of academics, policy makers and practitioners have recognised similarities between CCA and DRR [6], [24], [16], [25], [26], [27]. Both CCA and DRR emphasis on reducing vulnerability, which is a key similarity between the two practices ([25], [28]). In addition, both CCA and DRR are equally benefited in many ways. For example, DRR measures will reduce climate impact and climate measures will reduce disaster risk ([27], [28], [29]). Also, both disciplines use common non-structural measures, such as knowledge development/awareness methods and practices, including participatory mechanisms ([16], [25]). As a whole, both CCA and DRR are working towards achieving the same goal which is to reduce the vulnerability of societies.

\section{E. Current status and need for integration}

Four diverse communities working on DRR, CCA, environmental management and poverty reduction have made self-governing efforts to reduce socio-economic vulnerabilities to natural hazards. However, the efforts were not adequate to reduce the vulnerabilities of individuals and communities to natural disasters due to a lack of integration [26]. The only influence they had was on altering the social context within which these deviations occur [30]. Further, there is much conversation about the topic of integration, but very little research happens on how this can be achieved ([24], [31]). Hay [31] highlights that certain countries have analyzed the present low level of incorporation of DRR and CCA. While there may be institutional arrangements that propose some progress with incorporation at the national policy and institutional levels, the real-world reality is that little is happening on the ground at the ground level.

Part 3.4 of this section highlighted the synergies between CCA and DRR and Part 3.5 described the current status of integration efforts. It has emanated that both disciplines share similar values, but, since they are operated separately, there are lots of duplication of work and inefficiencies. Accordingly, there is a necessity to integrate CCA and DRR to reduce the vulnerability of societies, thereby creating resilient environments. Section 3.6 will discuss how the integration of CCA and DRR can create resilient environments and the challenges to integration in Asia will be discussed in Section 4.

\section{$F$. Resilient environment through the integration of CCA and DRR}

Part 3.4 and 3.5 of this section described how both CCA and DRR seek to reduce vulnerability. In disaster terms, vulnerability is defined as 'The conditions determined by physical, social, economic and environmental factors or processes which increase the susceptibility of an individual, a community, assets or systems to the impacts of hazards' [1] and is dependent on physical, social, environmental and economic factors [32]. As identified in Section 3.1, resilience is "the ability of a system, community or society exposed to hazards to resist, absorb, accommodate, adapt to, transform and recover from the effects of a hazard in a timely and efficient manner, including through the preservation and restoration of its essential basic structures and functions through risk management" [1]. This indicates, there is undisputedly a relationship between vulnerability and resilience ([33], [34], [35]), although the exact form of this relationship is not easily defined. Scientists have only recently started to investigate the linkages in recent decades, and the two have been conceptualized in various ways by different disciplines and theorists ([35],[36]). What we can assume here is, that the more vulnerable society is, the more susceptible, it is to a disaster, while the more resilient society is, the less likely it is a natural hazard will result in a major catastrophe. Therefore, there is an imperative to reduce vulnerability and increase resilience.

Decreasing vulnerability and increasing resilience requires the ability to implement effective changes to the system. In the setting of climate change, implementing adaptations to reduce vulnerability, leads to building resilience. The ability of a society to make adaptations is often termed 'adaptive capacity' and is defined as 'the capability of a (human) system to adjust to climate change (including climate variability and extremes), to moderate potential damages, to take advantage of opportunities, or to cope with the consequences" [32]. Available financial and human resources and adaptation options determine adaptive capacity. Caution should be taken, however, as not all actions to reduce vulnerability increase resilience and vice 
versa. Short-term resolutions for vulnerability reduction may compromise resilience in the long-term, while long-term adaptations need to take into account short-term realities and the needs of society. Addressing resilience and holistically vulnerability takes into consideration long-term drivers and local socio-economic priorities which in turn produces successful adaptations [36].

Several practical methods that address both reducing vulnerabilities and increasing resilience have been identified. These include vulnerability assessments to identify existing vulnerabilities; incorporating uncertainty into resilience planning to ensure resilience to potential future events; involving poor and marginalised groups in decision making to take into account vulnerabilities and identify adaptive capacities based on local knowledge, monitoring and evaluating actions, to ensure continuous improvement and scaling up those actions which prove to be successful [37].

The above discussion indicates that increasing the adaptive capacity will reduce vulnerability and increase resilience. Vulnerability and resilience are important concepts for both DRR and CCA and provide a potential link for integration [26]. For example, vulnerability is a key concept in both CCA and DRR [38]. From the above methods for reducing vulnerability and increasing resilience suggested by [37], similarities with the methods employed by DRR and CCA can be drawn; for example, both look to involve local and marginalized groups in decision making to increase capacity. DRR and CCA both analyze existing areas and causes of vulnerability to identify areas where the action is required. Both practices aim to support adaptive capacity through capacity building, and both share the same goal of increased resilience to natural hazards [26]. It could be suggested that CCA and DRR provide the vulnerability assessments and capacity building efforts required to increase resilience and minimize impacts of natural hazards, while vulnerability and resilience provide conceptual links to bring CCA and DRR together. In this way, vulnerability, resilience, CCA, and DRR are inextricably linked, therefore integrating CCA and DRR will support the creation of resilient environments.

\section{RESULTS AND DISCUSSION}

There are several challenges that hinder the integration of CCA and DRR in Asia. Based on both qualitative and quantitative analysis derived from the interviews, focus groups discussions and online questionnaire survey analysis, these can be categorized into five key challenge areas which are chaotic institutional set-up, political priorities, funding, stakeholder complexity, and communication barriers.

\section{A. Chaotic institutional set-up}

As derived from the qualitative analysis, the institutional set-up is one of the foremost barriers to CCA and DRR integration in Asia. In most Asian countries, CCA and DRR are separate portfolios operated by different ministries that are not keen to change their agendas to integrate CCA and DRR. Agencies on CCA and DRR want to work in their space, so there is less room for integration. Ideally, they should co-operate, but they are competing with each other to achieve specific goals.
The chaotic institutional set up does not only hinder the integration of CCA and DRR, but it has damaged the individual functions of CCA and DRR as well. Different organizations that have similar purposes not often do corporate with each other. The analysis identified key factors behind chaotic institution set up, including divergent government structures, non-allocation of clear roles and responsibilities among institutions, poor communication among organizations and a lack of stakeholder participation. In addition, it was highlighted that data management is weak in Asia in addition to a lack of qualified staff.

The quantitative analysis based on the RII value (Table 1 and 2) presents these factors with their ranking. The most prominent factor is ranked as 1 . The least prominent factor is ranked as 6.

TABLE I

VALUE-BASED RANKING FOR FACTORS BEHIND CHAOTIC INSTITUTIONAL ARRANGEMENTS FOR DRR.

\begin{tabular}{|l|c|c|}
\hline \multicolumn{1}{|c|}{ Factors } & RII & RANK \\
\hline Divergent governance structures & 0.810 & 4 \\
\hline $\begin{array}{l}\text { Unclear roles and } \\
\text { responsibilities }\end{array}$ & 0.862 & 2 \\
\hline $\begin{array}{l}\text { Poor communication between } \\
\text { organizations }\end{array}$ & 0.870 & 1 \\
\hline Lack of stakeholder participation & 0.769 & 6 \\
\hline Poor data management systems & 0.776 & 5 \\
\hline Lack of qualified staff & 0.776 & 5 \\
\hline
\end{tabular}

TABLE II

VALUE-BASED RANKING FOR FACTORS BEHIND CHAOTIC INSTITUTIONAL ARRANGEMENTS FOR CCA.

\begin{tabular}{|l|c|c|}
\hline \multicolumn{1}{|c|}{ Factors } & RII & RANK \\
\hline Divergent governance structures & 0.826 & 4 \\
\hline $\begin{array}{l}\text { Unclear roles and } \\
\text { responsibilities }\end{array}$ & 0.859 & 2 \\
\hline $\begin{array}{l}\text { Poor communication between } \\
\text { organizations }\end{array}$ & 0.869 & 1 \\
\hline Lack of stakeholder participation & 0.815 & 5 \\
\hline Poor data management systems & 0.836 & 3 \\
\hline Lack of qualified staff & 0.784 & 6 \\
\hline
\end{tabular}

The analysis further revealed vital factors that contribute to the current chaotic institutional set-up which hinders integration. In addition to the key factors described above, another four factors were identified. One of the critical factors for non-integration is a lack of political will to change or modify the existing chaotic institutional setup. It was also highlighted that even the institutions are not ready for a change to some extent. In addition, since these institutions are governed by different government departments and policies, they have different funding schemes. It is clear these institutes are not keen to change the current institutional setting and support a setting which acknowledges integration of CCA and DRR. Table 3 discusses RII based descriptive statistics as a percentage for each factor. Qualitatively derived factors were ranked on a scale from 1 to 10 , with 1 is the most affecting barrier and 10 being the least affecting barrier. 
TABLE III

INSTITUTIONAL BARRIERS PREVENTING CCA AND DRR INTEGRATION-RII RANKING

\begin{tabular}{|l|r|r|r|r|r|r|r|r|r|r|}
\hline \multicolumn{1}{|c|}{ Factors } & \multicolumn{1}{c|}{$\mathbf{1}$} & \multicolumn{1}{c|}{$\mathbf{2}$} & \multicolumn{1}{c|}{$\mathbf{3}$} & \multicolumn{1}{c|}{$\mathbf{4}$} & \multicolumn{1}{c|}{$\mathbf{5}$} & $\mathbf{7}$ & $\mathbf{8}$ & $\mathbf{9}$ & \multicolumn{1}{c|}{$\mathbf{1 0}$} \\
\hline Institutions are not ready & 16 & 4 & 12 & 8 & 20 & 8 & 8 & 4 & 8 & 12 \\
\hline Lack of political will & 20.8 & 33.3 & 16.6 & 8.3 & 8.3 & 8.3 & 4.1 & 0 & 0 & 0 \\
\hline $\begin{array}{l}\text { Separate funding sources and } \\
\text { allocations }\end{array}$ & 6.8 & 6.8 & 17.2 & 20.6 & 13.7 & 6.8 & 10.3 & 10.3 & 0 & 6.8 \\
\hline Legal frameworks and policies & 14.2 & 21.4 & 10.7 & 14.2 & 0 & 7.1 & 10.7 & 14.2 & 0 & 7.1 \\
\hline Divergent governance structures & 10.7 & 10.7 & 21.4 & 10.71 & 25 & 10.7 & 3.5 & 0 & 7.1 & 0 \\
\hline Unclear roles and responsibilities & 3.9 & 0 & 11.5 & 23.07 & 26.9 & 11.5 & 11.5 & 3.8 & 3.8 & 3.8 \\
\hline $\begin{array}{l}\text { Poor communication between } \\
\text { organisations }\end{array}$ & 3 & 4 & 2 & 1 & 3 & 6 & 4 & 6 & 0 & 1 \\
\hline $\begin{array}{l}\text { Poor communication between } \\
\text { organisations }\end{array}$ & 10 & 13.3 & 6.6 & 3.3 & 10 & 20 & 13.3 & 20 & 0 & 3.3 \\
\hline Lack of stakeholder participation & 9.6 & 3.2 & 0 & 9.6 & 6.4 & 12.9 & 19.3 & 19.3 & 12.9 & 6.4 \\
\hline Poor data management systems & 3.2 & 12.9 & 16.1 & 6.4 & 0 & 3.2 & 6.4 & 6.4 & 29.0 & 16.1 \\
\hline Lack of qualified staff & 6 & 9.1 & 3.03 & 9.09 & 3 & 15.1 & 6.0 & 15.1 & 12.1 & 21.2 \\
\hline
\end{tabular}

However, as derived from the qualitative analysis, some Asian countries have demonstrated best practice in combining CCA and DRR into singular government entities. The Philippines have shown the highest level of political confidence by bringing two legislative orders for both domains together. In Sri Lanka, the Department of Meteorology and the Disaster Management Centre are also governed by a single ministry.

\section{B. Political Priorities}

The qualitative analysis clearly indicated political priority as a key challenge for the integration of CCA and DRR in Asia. Since many Asian countries are still developing, politicians favor socio-economic development to DRR or CCA, and their disaster strategy is aimed more towards disaster response than disaster resilience. In many cases, communities expect socio-economic development rather than CCA or DRR. This further contributes to a lack of political will for integration.

In many countries, since CCA and DRR are under different institutions, there is a lack of political will, as politicians tend to consider matters only within their own ministry.

Further, it was discovered that at the state level, CCA receives much more attention than DRR as a result of two key global agreements. The Paris Agreement is a global agenda, agreed by the heads of state and is legally binding, whereas the Sendai Framework for Disaster Risk Reduction (SFDRR) is mainly dealt with by Disaster Management ministries and is not necessarily legally binding. Therefore, CCA has received state-level attention whereas DRR has only ministry level attention. On the other hand, for local political bodies in Asia, DRR is much more important than CCA as local political bodies are in direct contact with the people. Therefore they are more interested in DRR as they need to respond to the queries of the public. CCA is generally future-oriented. Therefore, local politicians cannot gain political points from CCA. As a result of these factors, CCA and DRR function as two separate disciplines in Asia, rather than receiving political attention for integration.

A lack of allocated funding for CCA and DRR integration emerged from the qualitative analysis. There are diverse funding allocations in Asia, but those are either for CCA or for DRR, but not specifically for programmes which seek to integrate CCA and DRR. Donors often focus more on science and evidence-based approaches than applied approaches. As a result, CCA gets more funding, as CCA is science and evidence-based. This is a typical scenario among the global funding bodies which support Asia. DRR is mainly seen from the humanitarian angle, but not from the development angle. Therefore, the funds are mainly issued for disaster response rather than for risk reduction. Further, another key issue in Asia is that some significant international funds are not suitable for the real needs at ground level. Therefore, in order to access funding, authorities need to follow guidelines which do not meet their exact requirements.

TABLE IV

RII RANKING FOR FACTORS BEHIND FUNDING ISSUES.

\begin{tabular}{|l|c|c|}
\hline \multicolumn{1}{|c|}{ Factors } & RII & Rank \\
\hline $\begin{array}{l}\text { Separate funding sources and } \\
\text { allocations for DRR and CAA }\end{array}$ & 0.757 & 7 \\
\hline $\begin{array}{l}\text { Legal frameworks and policies that } \\
\text { hinder allocation of funding }\end{array}$ & 0.763 & 6 \\
\hline Rigid monitoring and control & 0.660 & 13 \\
\hline Lack of compliance & 0.726 & 10 \\
\hline Lack of accountability & 0.711 & 12 \\
\hline Inadequate international grants & 0.718 & 11 \\
\hline Inadequate EU or regional grants & 0.730 & 9 \\
\hline $\begin{array}{l}\text { Inadequate donor funding } \\
\text { (international) }\end{array}$ & 0.731 & 8 \\
\hline Inadequate donor funding (national) & 0.774 & 5 \\
\hline $\begin{array}{l}\text { Lack of national/ central government } \\
\text { funding }\end{array}$ & 0.814 & 3 \\
\hline Lack of local government funding & 0.829 & 1 \\
\hline Lack of private sector participation & 0.820 & 2 \\
\hline $\begin{array}{l}\text { Stringent regulations on the public, } \\
\text { private partnerships }\end{array}$ & 0.786 & 4 \\
\hline
\end{tabular}

The quantitative analysis is based on RII value (Table 4) ranks 'non-availability of local government funding' for CCA and DRR integration as the dominant funding issue for integration. This indicates that CCA and DRR integration attempts should begin from the local government level as it 
is the lowest government level which is closer to the community. Secondly, this indicates a lack of public sector participation for CCA and DRR integration funding is an issue. This indicates that the private sector should have a donor perspective to integrate CCA and DRR.

\section{Stakeholder interest}

Cooperation among different stakeholders is crucial for integrating CCA and DRR, but unfortunately, the critical issue is most of the stakeholders in Asian countries are not keen to see CCA and DRR as integrated disciplines as indicated from the qualitative analysis. This is linked with the challenge chaotic institutional structure. As a result of chaotic institutional structures, stakeholders just want to work only in their space; they do not want to work in a holistic way. Therefore, there is no recognition of the importance of coordination among stakeholders.

Post-2015, the global agenda has provided a platform for CCA and DRR stakeholders. Before the SFDRR, there was significant separation between CCA and DRR stakeholders. For example, CCA stakeholders did not even want to attend DRR conferences. However, now things are changing for the better in Asia as a whole. In addition, politicians in Asia are now keen to attend both CCA and DRR activities after implementing the Framework. Similarly, donors are participating with interest in both CCA and DRR.

\section{Communication barriers}

Communication is another key barrier to CCA-DRR integration in Asia as revealed by the qualitative analysis. Communication barriers within CCA and DRR organizations is a crucial reason for non-integration as described in Section 4.1. In addition, there are communication issues between the academic community and practitioners. That is, new tools and techniques which are innovated from academic research are not generally transferred to practice. In many cases, new tools and techniques for CCA and DRR are practiced and evaluated only for academic research. When practitioners need to address issues related to CCA and DRR, they have to use similar old tools and techniques.

Furthermore, it was highlighted that there are difficulties integrating CCA at the community level as communities in some Asian countries are not aware of common terminology related to CCA and DRR. For example, in Thailand, there is no specific word for DRR. So, communicating this concept to the general public has become difficult. Further, it was highlighted that complex scientific information is difficult to transfer to common practice or the general public. There are further issues with the information flow to the general public in Asia. There are some mechanisms to communicate with the general public at the state level but, when it comes to the local or community level, the information is not transferred correctly due to reasons such as language issues. As a result of this, the integration of community-level DRR with CCA innovations has become extremely difficult. In addition, there are issues with the mode of communication. Generally, there are no specific guidelines to address the individual needs of communities such as communicating information to blind and deaf people and information sharing with people who are illiterate.

\section{CONCLUSIONS}

It is evident that the integration of CCA and DRR can contribute to the creation of resilient environments. Accordingly, acknowledgment for integration of CCA and DRR is prevalent. However, issues arise when it comes to actual integration, as there are a number of barriers that prevent integrating CCA and DRR. 'Poor communication between organizations' emerged as a critical barrier to integrating CCA and DRR. As revealed, in many Asian countries, CCA and DRR are placed within different ministerial portfolios where they tend to compete with each other rather than collaborating. Since CCA and DRR efforts are handled by two sets of organizations, their inherited cultures prevent or reduce effective integration. This lack of coordination between these organizations has resulted in large duplications. Furthermore, there are no funding schemes available in Asia to integrate CCA and DRR efforts. Instead, there are different funding schemes for CCA and DRR at global, regional and national levels, contributing to policy and institutional separation. It was also evident that there is a limited political will among those in the disaster management and environmental communities to integrate CCA and DRR mandates. One reason for this is that Asian countries are often more focused on socio-economic development than the integration of CCA and DRR as most of them are still developing nations. In addition, since much of Asia is developing, people focus on physical, socio and economic development activities, therefore, there is no incentive for politicians to put their efforts for CCA and DRR integration and tend to spend their time on other development related activities. Furthermore, a collaboration between different stakeholders and the sharing of information and knowledge among them is limited due to the chaotic institutional set-up. Further, within the current chaotic-institutional set-up communication among different authorities has become a barrier. Communicating DRR and CCA information to the community level is also weak in the Asian context, and since the information is not widely communicated, integration of CCA and DRR at the ground level has become difficult.

Based on the discussion which has been made throughout this paper, it can be noted that CCA and DRR integration is vital to creating resilient environments but, it is challenging to integrate CCA and DRR in Asia as there are several barriers which hinder the integration. Therefore, this paper provided insights to policymakers to rethink the need for integration of CCA and DRR to create resilient environments and thereby to restructure the current institutional and policy set up to provide a collaborative environment to integrate CCA and DRR.

\section{ACKNOWLEDGMENT}

This paper is based o the ESPREssO project findings. ESPREssO project has received funding from the European Union's Horizon 2020 research and innovation programme under grant agreement No 700342. This publication reflects the views only of the author, and the Commission cannot be held responsible for any use which may be made of the information contained therein. 


\section{REFERENCES}

[1] UNISDR (2017). Terminology. Available online: https://www.unisdr.org/we/inform/terminology - letter-d

[2] UNISDR, Climate Change Adaptation, and Disaster Risk Reduction: Institutional and Policy Landscape in Asia and the Pacific. United Nations Office for Disaster Risk Reduction, Panama (2010).

[3] World Bank (2011) Urban and Local Government. [Online]. Available:

http://web.worldbank.org/WBSITE/EXTERNAL/WBI/WBIPROGR AMS/CMUDLP/0,,contentMDK:20318381 pagePK:64156158 piP K:64152884 theSitePK:461754,00.html

[4] IPCC, Managing the Risk of Extreme Events and Disasters to Advance Climate Change Adaptation Intergovernmental Panel on Climate Change, Cambridge, UK 2012.

[5] W. Solecki, R. Leichenko, and K. O'Brien, "Climate Change Adaptation Strategies and Disaster Risk Reduction in Cities: Connections, Contentions, and Synergies," Current Opinion in Environmental Sustainability, vol. 3, pp. 135-141, 2011.

[6] J. Birkmann and K. von Teichman, "Integrating Disaster Risk Reduction and Climate Change Adaptation: Key Challenges-Scales, Knowledge, and Norms," Sustainability Science, vol. 5, pp. 171-184, 2010.

[7] GTZ and SUTP, "Sustainable Urban Transportation Project " International Journal of Global Environmental Issues, vol. 6, pp. 331-347, 2010.

[8] R. Shaw, A. Surjan, and G. A. Parvin, Urban Disaster and Resilience in Asia: Butterworth-Heinemann, 2016.

[9] World Bank, "Disaster Risk Management in South Asia: A Regional Overview," The World Bank, Washington D.C, USA2012.

[10] UNISDR, "How To Make Cities More Resilient- A Handbook For Local Government Leaders," United Nations Office for Disaster Risk Reduction, Geneva, Switzerland 2012.

[11] B. Manyena, G. O'Brien, P. O'Keefe, and J. Rose, "Disaster Resilience: A Bounce Back or Bounce Forward Ability?," Local Environment: The International Journal of Justice and Sustainability, vol. 16, pp. 417-424, 2011.

[12] D. Paton and D. M. Johnston, Disaster Resilience: An Integrated Approach. Springfield, USA: Charles C. Thomas Publisher Ltd., 2006

[13] B. Wisner, J. C. Gaillard, and I. Kelman, Handbook of Hazards and Disaster Risk Reduction and Management. Abingdon, UK: Routledge, 2012.

[14] S. A. Tabish and N. Syed, "Disaster Preparedness: Current Trends and Future Directions," International Journal of Science and Research (IJSR) vol. 4, pp. 227- 252, 2015.

[15] P. Blaikie, T. Cannon, I. Davis, and B. Wisner, At Risk: Natural Hazards, People's Vulnerability, and Disasters: Routledge, 2014

[16] J. Mercer, "Disaster Risk Reduction or Climate Change Adaptation: Are We Reinventing the Wheel?," Journal of International Development, vol. 22, pp. 247-264, 2010.

[17] D. E. Alexander, "Resilience and Disaster Risk Reduction: An Etymological Journey," Natural Hazards and Earth System Sciences, vol. 13, pp. 2707-2716, 2013

[18] W. J. Ammann, "Disaster Risk Reduction," in Encyclopedia of Natural Hazards, ed: Springer, 2013, pp. 170-175.

[19] I. Kelman, "Many Strong Voices: Outline for an Assessment Project Design," Center for International Climate and Environmental Research (CICERO) and UNEP/GRID-Arendal, Oslo, Norway2008.
[20] UNFCCC, "Climate Change: Impacts, Vulnerabilities, and Adaptation in Developing Countries," United Nations Climate Change Secretariat, Bonn, Germany2007.

[21] UNFCCC, "Technologies for Adaptation to Climate Change," United Nations Climate Change Secretariat, Bonn, Germany 2006.

[22] R. Burns and N. Machado des Johansson, "Disaster Risk Reduction and Climate Change Adaptation - A Sustainable Development Systems Perspective," Sustainability, vol. 9, p. 293, 2017.

[23] H. McGray, A. Hammill, R. Bradley, E. L. Schipper, and J.-E. Parry, "Weathering the Storm: Options for Framing Adaptation and Development," World Resources Institute, Washington D.C2007.

[24] A. Gero, K. Meheux, and D. Dominey-Howes, "Disaster Risk Reduction and Climate Change Adaptation in the Pacific: The Challenge of Integration," University of New South Wales, Sydney, 2010 .

[25] F. Sperling and F. Szekely, "Title," unpublished|

[26] F. Thomalla, T. Downing, E. Spanger-Siegfried, G. Han, and J. Rockström, "Reducing Hazard Vulnerability: Towards a Common Approach Between Disaster Risk Reduction and Climate Adaptation," Disasters, vol. 30, pp. 39-48, 2006.

[27] P. Venton and S. La Trobe, "Linking Climate Change Adaptation and Disaster Risk Reduction," Tearfund, Teddington, UK2008.

[28] T. Mitchell and M. van Aalst, "Convergence of Disaster Risk Reduction and Climate Change Adaptation," Department for International Development 31st October 20082008.

[29] Y. Lei and J. a. Wang, "A Preliminary Discussion on the Opportunities and Challenges of Linking Climate Change Adaptation with Disaster Risk Reduction," Natural Hazards, vol. 71, pp. 15871597, 2014

[30] N. Adger, S. Huq, K. Brown, D. Conway, and M. Hulme, "Adaptation to Climate Change in the Developing World," Progress in Development Studies, vol. 3, pp. 179-195, 2003.

[31] J. E. Hay, Disaster Risk Reduction \& Climate Change Adaptation in the Pacific: An Institutional and Policy Analysis. Suva, Fiju: UNISDR, UNDP, 2012.

[32] EEA. (2018). How to Assess Adaptive Capacity?[Online]. Available: http://climate-adapt.eea.europa.eu/knowledge/tools/adaptationsupport-tool/step-2-4

[33] N. Adger, "Vulnerability," Global Environmental Change, vol. 16, pp. 268-281, 2006.

[34] S. L. Cutter, L. Barnes, M. Berry, C. Burton, E. Evans, E. Tate, et al., "A Place-based Model for Understanding Community Resilience to Natural Disasters," Global Environmental Change, vol. 18, pp. 598606, 2008.

[35] G. C. Gallopin, "Linkages Between Vulnerability, Resilience and Adaptive Capacity," Global Environmental Change, vol. 16, pp. 293$303,2006$.

[36] Y. T. Maru, M. S. Smith, A. Sparrow, P. F. Pinho, and O. P. Dube, "A Linked Vulnerability and Resilience Framework for Adaptation Pathways in Remote Disadvantaged Communities," Global Environmental Change, vol. 28, pp. 337-350, 2014.

[37] M. Chaudhury, "Strategies for Reducing Vulnerability and Building Resilience to Environmental and Natural Disasters in Developing Countries," presented at the Expert Group Meeting on Strategies for Eradicating Poverty to Achieve Sustainable Development for All. , New York, 2017.

[38] F. Miller, H. Osbahr, E. Boyd, F. Thomalla, S. Bharwani, G. Ziervogel, et al., "Resilience and Vulnerability: Complementary or Conflicting Concepts?," Ecology and Society, vol. 15, p. 11, 2010. 